failure. Many workers confirmed and extended this finding, ${ }^{8-11}$ and immunofluorescence with human adrenal has become a useful diagnostic test for Addison's disease. The antibodies react with a cytoplasmic component of the adrenal cortical cells recovered in the "microsomal" fraction on ultracentrifugation and which is probably part of a lipoprotein membrane since the antigen behaves biochemically, ${ }^{12}$ like the parallel microsomal antigens of the thyroid and the gastric parietal cells. Adrenal fluorescence is obtained with the sera of about $50 \%$ of patients with idiopathic adrenal atrophy. In one series ${ }^{11}$ up to $80 \%$ of female patients gave positive results, though male patients showed a much lower incidence. Other authors report a higher rate of success with recent diagnosis. ${ }^{13}$ All agree that adrenal antibodies are rarely found in cases of tuberculous Addison's disease and in diseases not affecting the adrenal. But patients with idiopathic adrenal atrophy have a high incidence of other autoantibodies, including thyroid and gastric, ${ }^{11}$ antinuclear, and occasionally even mitochondrial antibodies. Recent work has shown that cellmediated immune responses play an important part in the destruction of adrenal cells, as they do also in autoallergic diseases affecting other organs. Thus, the circulating leucocytes of patients with Addison's disease are inhibited in their normal migration from capillary tubes by addition of adrenal antigen to the cell cultures, ${ }^{14}$ and in experimental adrenalitis in the rat it has been shown ${ }^{15}$ that passive transfer of sensitized lymph-node cells can produce lesions in the adrenal gland of intact animals.

In some cases of Cushing's syndrome the hyperactivity of the adrenal glands is associated with bilateral cortical hyperplasia in the absence of a pituitary or extra-pituitary A.C.T.H.-producing tumour, and this is reminiscent of the hypertrophy of the thyroid gland induced by the "longacting thyroid stimulator" (L.A.T.S.) in thyrotoxicosis. L.A.T.S. is now known to be an immunoglobulin (IgG), and it is possible that a similar stimulating autoantibody might be found in future in relation to this type of adrenal hyperplasia. It is therefore of interest that adrenal antibodies were found in a patient with Cushing's syndrome ${ }^{16}$ whose hyperactive

1 Carpenter, C. C. J., et al., Medicine, 1964, 43, 153.

Blizzard, R. M., Chee, D., and Davis, W., Clinical and Experimental Immunology, 1967, 2, 19 .

3 Wells, H. G., Archives of Pathology, 1930, 10, 499.

Barnett, E. V., Dumonde, D. C., and Glynn, L. E., Immunology, 1963, 6, 382.

${ }^{5}$ Steiner, J. W., Langer, B., Schatz, D. L., and Volpe, R., fournal of Experimental Medicine, 1960, 112, 187.

Witebsky, E., and Milgrom, F., Immunology, 1962, 5, 67.

Anderson, J. R., Goudie, R. B., Gray, K. G., and Timbury, G. C., Lancet, $1957,1,1123$

8 Blizzard, R. M., and Kyle, M., fournal of Clinical Investigation, 1963, $42,1653$.

Nerup, J., Søborg, M., Halberg, P., and Brøchner-Mortensen, K., Acta Medica Scandinavica, 1966, Suppl. No. 445, p. 383.

${ }^{10}$ Goudie, R. B., Anderson, J. R., Gray, K. G., and Whyte, W. G., Lancet, 1966, 1, 1173.

${ }^{11}$ Irvine, W. J., Stewart, A. G., and Scarth, L., Clinical and Experimental Immunology, 1967, 2, 31 .

12 Goudie, R. B., McDonald, E., Anderson, J. R., and Gray, K. G., Clinical and Experimental Immunology, $1968,3,119$.

${ }^{3}$ Wuepper, K. D., Wegienka, L. C., and Fudenberg, H. H., American fournal of Medicine, 1969, 46, 206 .

${ }^{14}$ Nerup, J., Andersen, V., and Bendixen, G., Clinical and Experimental Immunology, 1969, 4, 355 .

${ }^{15}$ Levine, S., and Wenk, E. J., American fournal of Pathology, 1968, $52,41$.

${ }^{16}$ Wegienka, L. C., Wuepper, K. D., Komarmy, L. E., and Forsham, P. H., Lancet, 1966, 1, 741.

${ }^{17}$ Anderson, J. R., Goudie, R. B., Gray, K. G., and Stuart-Smith, D. A., Clinical and Experimental Immunology, 1968, 3, 107.

18 Irvine, W. J., et al., Lancet, 1968, 2, 883.

19 Irvine, W. J., Chan, M. M. W., and Scarth, L., Clinical and Experimental Immunology, 1969, 4, 489.

${ }^{30}$ Spinner, M. W., Blizzard, R. M., and Childs, B., fournal of Clinical Endocrinology and Metabolism, 1968, 28, 795. adrenals showed focal lymphoid infiltration similar to that seen in the thyroid in Graves's disease.

One of the most interesting recent developments is the discovery by Anderson and colleagues ${ }^{17}$ of a second antigenantibody system in autoimmune adrenal disease which may explain some cases of associated ovarian atrophy with premature menopause. ${ }^{18}$ The antibodies react with the cytoplasm of adrenal cells and also with steroid-producing cells in the ovary, testis, and placenta. ${ }^{17} \mathrm{~W}$. J. Irvine and colleagues $^{19}$ have made a detailed analysis of this new family of autoantibodies, and it seems that several components of the steroid-producing cells react with them. Most of the patients with serum antibodies to ovarian antigens suffered from premature menopause and probable ovarian atrophy. However, the few male patients whose serum reacted with testicular antigens have shown no evidence of clinical hypogonadism so far. ${ }^{17}$

Thus there is strong evidence to suggest that "idiopathic" adrenal atrophy is an organ-specific primary autoimmune disease belonging to the same category as Hashimoto's thyroiditis and autoimmune gastritis. Family studies have shown an increased incidence of these diseases in relatives of patients with Addison's disease, ${ }^{13}$ though there may be a second variety of familial adrenal deficiency, possibly due to enzyme defects, in which autoimmune mechanisms are not at work. $^{20}$

\section{Anaesthesia in the Dark}

Death under anaesthesia is bad enough during an attempt to remove a massive tumour or to deal with overwhelming injuries ; but it is still worse when a patient dies while undergoing a minor operation.

Cardiac arrest in a previously healthy subject during such a procedure is almost always the result of hypoxia. This may be due to airway obstruction, a fault in the anaesthetic apparatus, an empty oxygen cylinder, or a whole variety of other mishaps which can usually be avoided or anticipated by constant alertness on the part of the anaesthetist. A great deal of this vigilance depends on observation-the observation of the patient's colour and his breathing, and of the dials and flow meters on the anaesthetic monitoring equipment.

Unfortunately, some surgeons and radiologists even today make the anaesthetist's task a difficult one by asking for conditions mimicking a war-time blackout during such procedures as endoscopies, retinoscopy, and angiography. Always helpful, the anaesthetist tries to provide his colleague with an efficient anaesthetic service during these apparently necessary circumstances of darkness, and as a result he is forced to supervise his patient in considerably less than ideal surroundings. He has to rely either on such means as keeping a hand on the chest of the patient to monitor respirations, ingenious arrangements of luminous dials, or, as recently suggested ${ }^{1}$ by $S$. Mehta, luminous dots and lines painted on the rebreathing bag.

J. A. Lee has pointed out ${ }^{2}$ that very few examinations require more than dimming of the theatre lights, and notes that anaesthetists, who probably perform more "'oscopies"

1 Mehta, S., British fournal of Anaesthesia, 1969, 41, 465.

2 Lee, J. A., British fournal of Anaesthesia, 1969, 41, 641 . 
with the laryngoscope than anyone else, carry out this examination satisfactorily provided that they do not compete with the slanting rays of the sun shining down the barrel of the instrument.

Today there is little excuse for forcing an anaesthetist to work in the dark. Modern fibreoptics provide brilliant illumination during endoscopy, and image intensifiers make radiographic visualization clear in a reasonably lit department. Dr. Lee makes out a good case for anaesthetists refusing to work in complete darkness; their job is often difficult enough in the light.

\section{Actinic Reticuloid}

The dermatoses which affect exposed skin and are made worse by light present formidable diagnostic and therapeutic problems, and these conditions are getting more common. More and more skin is seen in the street every year as the amount of the body covered by clothes is reduced by trends of fashion. At the same time, the range of chemicals, used topically or systemically, which have proved to have photosensitizing properties has also increased.

The adequate investigation (as distinct from the mere confirmation of a diagnosis) of apparent photosensitivity requires elaborate equipment and makes heavy demands on the time of both physician and patient. This limits the numbers of clinical photobiological centres, but this limitation has had the advantage of attracting to these few centres clinical problems from many parts of the country, thus making it possible to define and elucidate syndromes which are relatively rare.

Dr. Magnus and his colleagues at the Institute of Dermatology in London" have recently characterized as "actinic reticuloid" a syndrome which most dermatologists have probably encountered and will remember as a source of therapeutic frustration. The patients described were 10 elderly men with a chronic eczematous eruption predominantly affecting the exposed skin of the face, hands, and forearms, but often affecting also the relatively shaded areas of the neck and extending to contiguous covered skin on the arms and elsewhere. Most patients had episodes in which there was almost universal erythroderma. In long-standing or severe cases oedematous plaques produced gross furrowing and distortion of the features, and lichenoid papules and plaques often added a further distinctive feature.

The eruption cleared slowly when the patients were confined to an almost completely darkened room and relapsed rapidly on re-exposure to daylight. Most patients were not aware that the condition was made worse by light, partly because there was no obvious seasonal fluctuation in its severity, partly because exposure to daylight, as distinct from full sunlight, was sufficient to provoke or perpetuate it, and partly because in some cases fluorescent tube lighting could also induce relapses. The condition proved resistant to many forms of treatment-chloroquine and methotrexate systemically and steroids, sunscreening creams, and grenz-rays topic-

\footnotetext{
1 Ive, F. A., Magnus, I. A., Warin, R. P., and Jones, E. W., British fournal of Dermatology, 1969, 81, 469.

- Brown, S., Lane, P. R., and Magnus, I. A., British Fournal of Dermatology, 1969, 81, 420.

3 Crow, K. D., Wilkinson, D. S., and Osmundsen, P. E., British fournal of Dermatology, 1969, 81, 180 .
}

ally-and was so incapacitating that many of the patients developed reactive depression and no fewer than five had attempted suicide.

The histological changes in the affected skin were remarkable. The density and character of the cellular infiltrate suggested a reticulosis with features resembling Hodgkin's disease or mycosis fungoides, but though abnormal lymphoid cells were numerous mitotic figures were rare, and though there were many giant cells none of the characteristic Hodgkin's type were found. Nevertheless the simulation of a reticulosis was sufficiently close to cause real anxiety and would confound the inexperienced or unwary.

The quantitative asessment of the photosensitivity of these patients also gave results which were interesting and unusual. The patients produced an erythematous and oedematous response to small doses of the sunburn wavelengths but also a morphologically abnormal response with long-wave ultraviolet light and even with visible light. The sensitivity to long ultraviolet wavelengths explains the exacerbations that some patients rightly attributed to fluorescent lighting. ${ }^{2}$

This syndrome is sufficiently distinctive to be readily identifiable in all but its earliest stages. The early or mild case must be differentiated from photocontact dermatitis, such as may be induced by the halogenated salicylanilides in soaps ${ }^{3}$ and from certain forms of simple allergic contact dermatitis, notably that caused by chrysanthemums and some botanically related plants. However, all such dermatoses fluctuate in severity in relation to the seasonal occurrence of the allergen or of sufficiently bright sunshine. Actinic reticuloid is remorselessly persistent unless the patient lives in almost total darkness.

The cause and nature of actinic reticuloid are unknown. The remission of symptoms which consistently follows avoidance of light makes it improbable that the syndrome is in fact a prereticulosis, but it would be premature to exclude the possibility.

\section{Invasion of Privacy}

One of the acknowledged defects in English law is the lack of any redress for invasion of privacy. Nothing can be done to stop a newspaper printing an embarrassing photograph no matter how obtained. "Public interest" is the excuse offered on such occasions; and last week the Press Council followed this convention when it rejected a complaint by the relatives of a patient who had been named by the Daily Telegraph as the recipient of a heart transplant despite their requests for anonymity.

By their code of ethics doctors assure patients that consultation and treatment will be kept confidential. Any patient should be able to be certain that his presence in hospital, his diagnosis, and his treatment will be kept secret if he so wishes. A newspaper can always ferret out the identity of a patient if it tries hard enough, but for it to print the facts-especially when it does so against the expressed wishes of the patient or his close relatives-is an intrusion into the doctor-patient relationship. This must be wrong. The only exception is that of personalities in the public eye whose state of health in general terms is legitimately of public concern. Last week the Press Council betrayed the standards it was set up to advance. 